\title{
Outcomes of decompression and fusion for treatment of spinal infection
}

\author{
Nicholas Dietz, BS, ${ }^{1}$ Mayur Sharma, MD, MCh, ${ }^{1}$ Ahmad Alhourani, MD, ${ }^{1}$ \\ Beatrice Ugiliweneza, PhD, MSPH, ${ }^{1}$ Dengzhi Wang, MS, ${ }^{1}$ Miriam Nuño, PhD, ${ }^{2}$ Doniel Drazin, MD, ${ }^{3}$ \\ and Maxwell Boakye, MD, MPH, MBA ${ }^{1}$
}

'Department of Neurosurgery, University of Louisville, Louisville, Kentucky; ${ }^{2}$ Department of Public Health Sciences, Division of Biostatistics, University of California, Davis, California; and ${ }^{3}$ Evergreen Hospital Neuroscience Institute, Kirkland, Washington

OBJECTIVE Spine infection including vertebral osteomyelitis, discitis, paraspinal musculoskeletal infection, and spinal abscess refractory to medical management poses significant challenges to the treating physician. Surgical management is often required in patients suffering neurological deficits or spinal deformity with significant pain. To date, best practices have not been elucidated for the optimization of health outcomes and resource utilization in the setting of surgical intervention for spinal infection. The authors conducted the present study to assess the magnitude of reoperation rates in both fusion and nonfusion groups as well as overall health resource utilization following surgical decompression for spine infection.

METHODS The authors performed an analysis using MarketScan (2001-2015) to identify health outcomes and healthcare utilization metrics of spine infection following surgical intervention with decompression alone or combined with fusion. Adult patients underwent surgical management for primary or secondary spinal infection and were followed up for at least 12 months postoperatively. Assessed outcomes included reoperation, healthcare utilization and payment at the index hospitalization and within 12 months after discharge, postoperative complications, and infection recurrence.

RESULTS A total of 2662 patients in the database were eligible for inclusion in this study. Rehospitalization for infection was observed in $3.99 \%$ of patients who had undergone fusion and in $11.25 \%$ of those treated with decompression alone. Reoperation was needed in $12.7 \%$ of the patients without fusion and $8.16 \%$ of those with fusion. Complications within 30 days were more common in the nonfusion group (24.64\%) than in the fusion group (16.49\%). Overall postoperative payments after 12 months totaled $\$ 33,137$ for the nonfusion group and $\$ 23,426$ for the fusion group.

CONCLUSIONS In this large cohort study with a 12-month follow-up, the recurrence of infection, reoperation rates, and complications were higher in patients treated with decompression alone than in those treated with decompression plus fusion. These findings along with imaging characteristics, disease severity, extent of bony resection, and the presence of instability may help surgeons decide whether to include fusion at the time of initial surgery. Further studies that control for selection bias in appropriately matched cohorts are necessary to determine the additive benefits of fusion in spinal infection management.

https://thejns.org/doi/abs/10.3171/2018.10.FOCUS18460

KEYWORDS surgical site infection; spinal infection; complications; decompression; fusion

$\mathrm{S}$ PINE infection including vertebral osteomyelitis, discitis, paraspinal musculoskeletal infection, and spinal abscess represents an insidious pathology with potentially devastating consequences, often requiring neurosurgical intervention. Delayed diagnosis of spinal infection after 3 months of symptom onset ${ }^{23}$ has been shown to increase mortality to rates as high as $20 \% .^{28}$ The incidence of primary or secondary spine infection is 1 case in 100,000 persons ${ }^{2}$ annually, with rising rates in recent years ${ }^{30}$ likely due to increased intravenous drug use and an aging population with chronic disease and degenerative spinal conditions. ${ }^{32}$ While etiologies vary, the most commonly isolated pathogen in pyogenic spine infection is Staphylococcus aureus (in up to $41 \%-80 \%$ of infections), ${ }^{6,12}$ followed by Staphylococcus epidermidis and gram-negative organisms, including Escherichia coli. ${ }^{27}$ 
TABLE 1. ICD-9 and ICD-10 codes used for extracting diagnoses of spinal infection from the database

\begin{tabular}{|c|c|c|}
\hline Diagnosis & ICD-9 Code & ICD-10 Code \\
\hline Cellulitis \& abscess of unspecified sites & 682.9 & L02.91 \\
\hline Intraspinal abscess & 324.1 & G06.1, G06.2 \\
\hline Tuberculous abscess of brain \& spinal cord & $013.5 x, 015.00$ & A17.81 \\
\hline Osteomyelitis, unspecified & $730.00,730.10,730.18,730.19,730.20,730.28,730.29$ & M86.9, M46.20 \\
\hline Discitis, unspecified, site unspecified & $722.91-93$ & M46.40 \\
\hline Infection of intervertebral disc (pyogenic), lumbar region & 730.98 & M46.36, M46.32-34 \\
\hline Psoas abscess & 567.31 & K68.12 \\
\hline Retroperitoneal abscess & 567.38 & K68.19 \\
\hline $\begin{array}{l}\text { Infection \& inflammatory reaction due to other internal orthopedic } \\
\text { device, implant, \& graft }\end{array}$ & 996.67 & T84.63XA \\
\hline Other postop infection & 998.59 & T81.4XXA \\
\hline Retropharyngeal abscess & 478.24 & J39.0, J93 \\
\hline
\end{tabular}

Conservative management involves identification of the pathogen through blood culture or percutaneous biopsy, aggressive antibiotic treatment, and bracing. ${ }^{28}$ However, a certain subset of spine infection that is related to failed medical management, sepsis, neurological deficit, significant pain, need for open biopsy, or risk of spinal deformity may require more extensive surgical management for resolution and stabilization., ${ }^{4,28}$ Spinal epidural abscess, another rare spinal infection, has traditionally been treated with surgical drainage to avoid neurological deterioration and complication. ${ }^{1,5}$ Surgical treatment involves debridement of necrotic or infected tissue and irrigation with an antibiotic regimen tailored to treat the responsible pathogen. ${ }^{33}$ Decompression of neural elements and restoration of alignment and stabilization are additional considerations for more extensive surgical treatments. ${ }^{4}$ After extensive resection of infected areas, bone graft fusion and instrumentation are necessary to bridge the large bony defects and stabilize the spine. Indeed, fusion with graft and internal fixation for refractory pyogenic discitis and vertebral osteomyelitis has been shown to be efficacious in resolving infection, restoring functional mobility, and reducing pain. ${ }^{17,21}$

Considering the clinical challenge inherent to this condition, it is surprising that there is little evidence in the literature regarding reoperation rates following decompression without fusion in a large patient cohort. The present study represents the first analysis of outcomes of spinal fusion and nonfusion in a large cohort of patients with spinal infection who underwent surgical decompression with a 12-month postoperative follow-up. Our overall goal was to assess the magnitude of reoperation rates in both fusion and nonfusion groups. A secondary goal was to assess overall health resource utilization following surgical decompression for infection. Postoperative considerations such as reoperation rates, complications, hospitalizations, and overall healthcare utilization metrics are described.

\section{Methods \\ Data Source}

We used MarketScan claims data from Truven Health
Analytics. MarketScan is a data set containing paid claims of over 20 billion records ${ }^{10}$ from about 350 payers to date, including large employers, health plans, and government and public organizations. It has been used in medical research since the $1990 \mathrm{~s}^{10}$ Researchers can obtain these data for a fee. The richness of this data set resides in its details of clinical encounters and inclusion of patient claims from all over the country. However, the population in the data is composed of Medicare, Medicaid, and privately insured individuals (employees and their dependents, early retirees, Consolidated Omnibus Budget Reconciliation Act [COBRA] participants, and retirees with Medigap). MarketScan contains multiple files linked with a unique patient identification number, representing the patients' trajectories through the healthcare system. ${ }^{8}$ For this study, we used the inpatient, outpatient, and medication files for the years 2001-2015.

\section{Patient Selection}

From the inpatient admission tables, we extracted cases with a primary diagnosis of spinal infection and a concurrent procedure of decompression within the same hospitalization. These cases were then divided into two groups: decompression without fusion and decompression with fusion. Exclusion criteria consisted of a concurrent refusion claim or an age under 18 years old. This extraction, performed using ICD-9, ICD-10, and Current Procedural Terminology (CPT)-4 codes, is detailed in Table 1. The first case satisfying these conditions for each patient was labeled the index hospitalization.

\section{Explanatory Variables, Enrollment Period, and Follow-Up Period}

Patient characteristics such as age, sex, year of index hospitalization, insurance type (commercial, Medicaid, Medicare), comorbidities, instrumentation, and number of levels at the index hospitalization were the explanatory variables in this study. Comorbidity was measured with the Elixhauser Comorbidity Index, ${ }^{7}$ by which scores were calculated based on modified ICD-9 and ICD-10 codes (Quan et al. ${ }^{22}$ ).

To calculate the insurance enrollment period and the 
TABLE 2. ICD-9 and ICD-10 codes used for extracting complications from the database

\begin{tabular}{|c|c|c|}
\hline Complication Type & ICD-9 Code & ICD-10 Code \\
\hline Renal & $584,584.5-584.9,997.5$ & N17.x, N99.89 \\
\hline Cardiac & $\begin{array}{l}997.1,410.0,410.00,410.01,410.1,410.10,410.11,410.2,410.20 \\
\quad 410.21,410.3,410.30,410.31,410.4,410.40,410.41,410.5 \\
410.50,410.51,410.6,410.60,410.61,410.7,410.70,410.71 \\
410.8,410.80,410.81,410.9,410.90,410.91\end{array}$ & 121.x, 197.7xx, 197.8xx \\
\hline Nervous system & $997.00-997.09$ & G97.xx \\
\hline Cerebrovascular disease & 430.xx-436.xx, 438.2x-438.5x & $160 . x x-169 . x x$ \\
\hline $\begin{array}{l}\text { Deep vein thrombosis \& pul- } \\
\text { monary embolism }\end{array}$ & $\begin{array}{l}\text { 415.1, 415.11, 415.19, 451.11, 415.11, 451.19, 451.12, 451.81, 451.9, } \\
\quad \text { 453.4, 453.40, 453.41, 453.42, 453.8, 453.9 }\end{array}$ & 126.xx, I80.xx, I81.xx, I82.xx \\
\hline Pulmonary & $518.4,518.5,518.81,518.82,997.3,997.31,997.39$ & J81.0, J80, J95.1, J95.2, J95.3, J95.8xx, J96.xx \\
\hline Infection & $595.0,595.9,599.0$ & N30.00, N30.01, N30.90, N30.91, N39.0 \\
\hline Wound & $998.32,998.51,998.6,998.81,998.83,998.2$ & $\begin{array}{l}\text { T81.31xx, T81.4xxx, T81.8xxx, G97.4x, D78.12, } \\
\text { D78.11, E361.2, H59.229, I97.52, J95.72, } \\
\text { K91.72, L76.12, M96.821, N99.72 }\end{array}$ \\
\hline Hydrocephalus & $331.3-331.5$ & G91.x \\
\hline Laceration & 998.2 & $\begin{array}{l}\text { G97.4x, D78.1x, E36.12, H59.229, 197.52, J95.72, } \\
\text { K91.72, L76.12, M96.821, N99.72 }\end{array}$ \\
\hline Rhinorrhea & 349.81 & G96.0 \\
\hline Pneumonia & 481.xx, 482.xx, 486.xx & $\mathrm{J} 13-\mathrm{J} 18 . \mathrm{x}$ \\
\hline
\end{tabular}

follow-up time, we used the difference between the surgery dates and the dates of start and end enrollment times as follows: preindex enrollment period was the difference between surgery admission date and start enrollment date, and postindex follow-up time was the difference between end enrollment date and surgery discharge date. In cases in which the start enrollment date or end enrollment date was missing, we substituted it, respectively, with the very first or the very last claim of the individual in the data.

\section{Index Hospitalization and Postdischarge Outcomes}

The outcomes of interest were reoperation, healthcare utilization and payment at the index hospitalization and within 12 months after discharge, as well as repeat surgery within 12 months. A claim was classified as repeat surgery if it was for a new fusion, revision fusion, or new decompression within 12 months after discharge. We also looked at complications during the index hospitalization and within 30 days after discharge, as well as emergency room visits within 30 days.

We looked at outcomes during the index hospitalization and within 1 and 12 months after discharge. Index hospitalization outcomes were length of stay, discharge disposition, and complications (renal complication, cardiac complication, general neurosurgical complication, general neurological complication, deep vein thrombosis or pulmonary embolism, pulmonary complication, infection, wound infection, hydrocephalus, mechanical ventilation, laceration, or cerebrospinal fluid rhinorrhea). The ICD-9 codes used to search for complications are listed in Table 2.

Postdischarge outcomes were healthcare resources use (hospital readmission rates and counts, outpatient services count, and medication refills) and their associated healthcare resources payments. We also evaluated emer- gency department visits and complications at 1 month after decompression. For the index hospitalization, resource use included length of stay and discharge admission. For postdischarge health resource use outcomes, resources use included 30-day emergency department use, hospital readmission, 12-month hospital admissions, outpatient services, and medication refills.

All payments associated with the healthcare utilization described above were included: index hospitalization payment and postdischarge inpatient, outpatient, and medication payments. Payments were cumulated over all hospitalizations (inpatient payments), all outpatient services (outpatient payments), all prescription medication refills (medications payments), and a combination of all three. To make payments comparable, they were all inflated to 2016 US dollars using the medical component of the consumer price index (accessible through the United States Bureau of Labor Statistics website ${ }^{20}$ ).

\section{Statistical Analysis}

We summarized continuous variables with means and standard deviations, medians and interquartile ranges, as well as the full range (minimum to maximum). For categorical variables, we used frequency counts and percentages. Data preprocessing and analysis were performed using SAS 9.4 software (SAS Institute Inc.). ${ }^{29}$

\section{Results \\ Patient Demographics}

A total of 2662 patients with a median age of 55 years (range 18-92 years) and a diagnosis of spinal infection were identified in the Truven Health MarketScan database and met our study inclusion criteria (Fig. 1 and Table 3). The decompression group without fusion (2086 


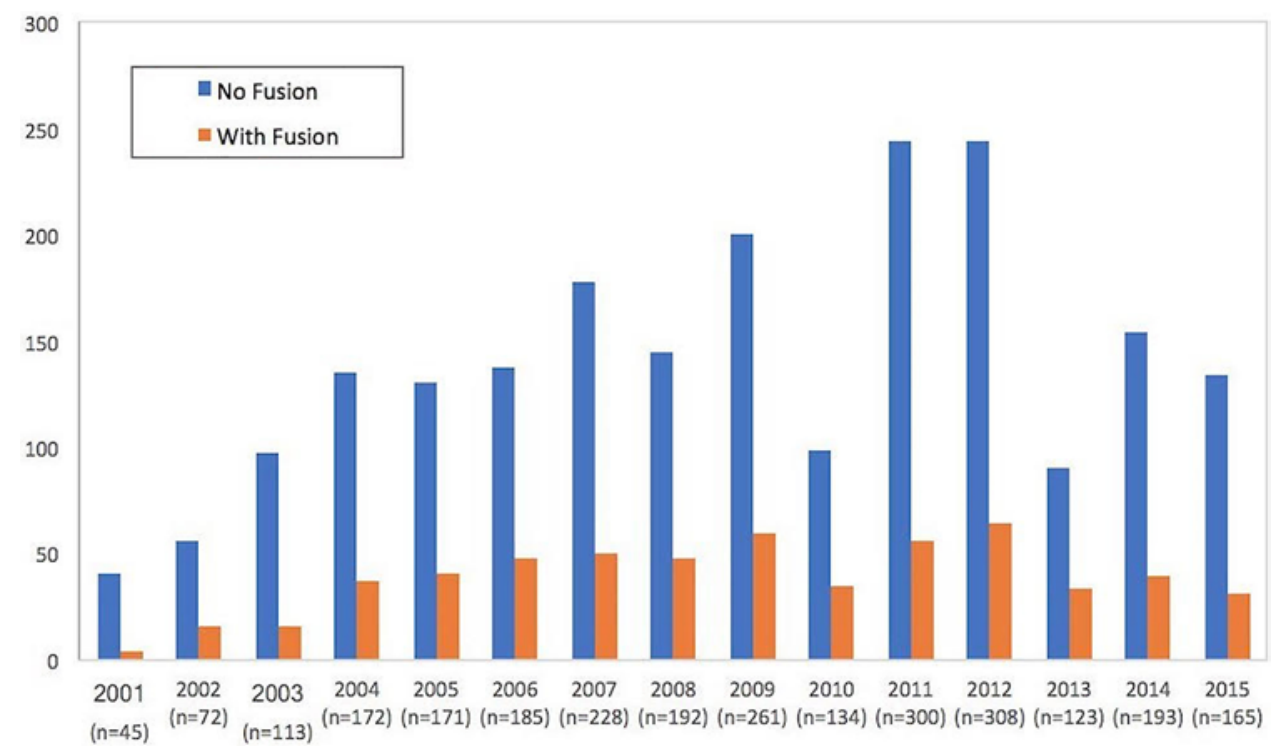

FIG. 1. Bar graph showing trends (2001-2015) in the incidence of spinal infection treated with decompression plus fusion versus decompression alone.

patients) represented $78.36 \%$ of the study cohort, and the decompression group with fusion (576 patients) made up $21.64 \%$ of the cohort. The percentage of females was higher for the fusion group (54.51\%) than for the nonfu-

TABLE 3. Demographics, insurance, and Elixhauser Comorbidity Index across treatment groups

\begin{tabular}{|c|c|c|}
\hline Variable & w/o Fusion & w/ Fusion \\
\hline No. $(\%)$ & $2086(78.36 \%)$ & $576(21.64 \%)$ \\
\hline \multicolumn{3}{|l|}{ Demographics } \\
\hline \multicolumn{3}{|l|}{ Age in yrs } \\
\hline Mean (SD) & $55.5(13.1)$ & $56.3(11.4)$ \\
\hline Median (IQR) & $56(48,63)$ & $57(50,62)$ \\
\hline Range, min-max & $18-92$ & $20-87$ \\
\hline Female sex, no. (\%) & $1009(48.37 \%)$ & $314(54.51 \%)$ \\
\hline \multicolumn{3}{|l|}{ Insurance, no. (\%) } \\
\hline Commercial & $1326(63.57 \%)$ & $403(54.51 \%)$ \\
\hline Medicaid & $345(16.54 \%)$ & $58(10.07 \%)$ \\
\hline Medicare & $415(19.89 \%)$ & $115(19.97 \%)$ \\
\hline \multicolumn{3}{|c|}{ Elixhauser Comorbidity Index, no. (\%) } \\
\hline 0 & $595(28.52 \%)$ & $189(32.81 \%)$ \\
\hline 1 & $587(28.14 \%)$ & $172(29.86 \%)$ \\
\hline 2 & $388(18.60 \%)$ & $117(20.31 \%)$ \\
\hline $3+$ & $516(24.74 \%)$ & $98(17.01 \%)$ \\
\hline Wound infection: yes, no. (\%) & $529(25.36 \%)$ & $35(6.08 \%)$ \\
\hline Op w/in 1 yr prior: yes no. (\%) & $634(30.39 \%)$ & $92(15.97 \%)$ \\
\hline Prior opioid abuse: yes, no. (\%) & $935(44.82 \%)$ & $292(50.69 \%)$ \\
\hline Prior IV drug abuse: yes, no. (\%) & $115(5.51 \%)$ & $15(2.60 \%)$ \\
\hline Tobacco use: yes, no. (\%) & $371(17.79 \%)$ & $89(15.45 \%)$ \\
\hline Diabetes: yes, no. (\%) & $575(27.56 \%)$ & $140(24.31 \%)$ \\
\hline CHF: yes, no. (\%) & $143(6.86 \%)$ & $29(5.03 \%)$ \\
\hline
\end{tabular}

$\mathrm{CHF}=$ congestive heart failure; $\mathrm{IQR}=$ interquartile range; $\mathrm{IV}=$ intravenous. sion group (48.37\%). Differences in insurance coverage were also significant between the two groups (fusion vs nonfusion): commercial insurance (69.97\% vs $63.57 \%$ ), Medicaid (10.07\% vs $16.54 \%$ ), and Medicare (19.97\% vs $19.89 \%$ ). Tobacco use was present in $17.79 \%$ of the nonfusion group and $15.45 \%$ of the fusion group. Congestive heart failure was present in $6.86 \%$ of the nonfusion group and $5.03 \%$ of the fusion group. Diabetes was more prevalent in the nonfusion group $(27.56 \%)$ than in the fusion group (24.31\%).

\section{Clinical and Surgical History}

The Elixhauser Comorbidity Index was used as a measure of comorbid medical history among patients and was found to be different between the treatment groups (Table 3 ). The fusion and nonfusion groups had the greatest disparity for the Elixhauser Comorbidity Index 3 or greater ( $17.01 \%$ vs $24.74 \%$, respectively). Moreover, patients in the nonfusion group were more likely to have undergone prior spine surgery within 12 months of the decompression than those in the fusion group $(30.39 \%$ vs $15.97 \%$, respectively). Patients in the nonfusion group were also more likely to have postoperative infection than those in the fusion group ( $25.36 \%$ vs $6.08 \%$, respectively). Patients with fusion were more likely to have had prior opioid abuse (50.69\% vs $44.82 \%$, respectively). Prior intravenous drug abuse was present in $2.6 \%$ and $5.51 \%$ of the fusion and nonfusion groups, respectively. Separate subanalyses were conducted for the fusion and nonfusion groups that had undergone versus had not undergone spine surgery in the 12 months before decompression for spinal infection (Tables 4 and 5).

\section{Primary Outcomes}

New infection was less likely to occur in the fusion group than in the nonfusion group $(3.99 \%$ vs $11.25 \%$, respectively; Table 6). New fusion was also less likely in the 
TABLE 4. Demographics, insurance, and Elixhauser Comorbidity Index across treatment groups with and without surgery prior to decompression for spinal infection

\begin{tabular}{|c|c|c|c|c|}
\hline \multirow[b]{2}{*}{ Variable } & \multicolumn{2}{|c|}{ No Op in 12 Mos Prior to Decompression } & \multicolumn{2}{|c|}{ Op in 12 Mos Prior to Decompression } \\
\hline & w/o Fusion & w/ Fusion & w/o Fusion & w/ Fusion \\
\hline No. $(\%)$ & $1452(75 \%)$ & $484(25 \%)$ & $634(87.33 \%)$ & $92(12.67 \%)$ \\
\hline \multicolumn{5}{|l|}{ Demographics } \\
\hline \multicolumn{5}{|l|}{ Age in yrs } \\
\hline Mean (SD) & $56.4(13.4)$ & $56.6(11.5)$ & $53.3(12.2)$ & $55(10.5)$ \\
\hline Median (IQR) & $57(49,64)$ & $57(50,63)$ & $54(45,61)$ & $57(48,61)$ \\
\hline Range, min-max & $18-92$ & $23-87$ & $18-90$ & $20-82$ \\
\hline Female sex, no. (\%) & $712(49.04 \%)$ & $267(55.17 \%)$ & $297(46.85 \%)$ & $47(51.09 \%)$ \\
\hline \multicolumn{5}{|l|}{ Insurance, no. (\%) } \\
\hline Commercial & $874(60.19 \%)$ & $330(68.18 \%)$ & $452(71.29 \%)$ & $73(79.35 \%)$ \\
\hline Medicaid & $255(17.56 \%)$ & $50(10.33 \%)$ & $90(14.20 \%)$ & $8(8.7 \%)$ \\
\hline Medicare & $323(22.25 \%)$ & $104(21.49 \%)$ & $92(14.51 \%)$ & $11(11.96 \%)$ \\
\hline \multicolumn{5}{|c|}{ Elixhauser Comorbidity Index, no. (\%) } \\
\hline 0 & $405(27.89 \%)$ & $160(33.06 \%)$ & $190(29.97 \%)$ & $29(31.52 \%)$ \\
\hline 1 & $404(27.82 \%)$ & $144(29.75 \%)$ & $183(28.86 \%)$ & $28(30.43 \%)$ \\
\hline 2 & $267(18.39 \%)$ & $101(20.87 \%)$ & $121(19.09 \%)$ & $16(17.39 \%)$ \\
\hline $3+$ & $376(25.90 \%)$ & $79(16.32 \%)$ & $140(22.08 \%)$ & $19(20.65 \%)$ \\
\hline Wound infection: yes, no. (\%) & $82(5.65 \%)$ & $22(4.55 \%)$ & $447(70.5 \%)$ & $13(14.13 \%)$ \\
\hline Prior opioid abuse: yes, no. (\%) & $549(37.81 \%)$ & $233(48.14 \%)$ & $386(60.88 \%)$ & $59(64.13 \%)$ \\
\hline Prior IV drug abuse: yes, no. (\%) & $73(5.03 \%)$ & $15(3.10 \%)$ & $42(6.62 \%)$ & $0(0 \%)$ \\
\hline Tobacco use: yes, no. (\%) & $226(15.56 \%)$ & $73(15.08 \%)$ & $145(22.87 \%)$ & $16(17.39 \%)$ \\
\hline Diabetes: yes, no. (\%) & $410(28.24 \%)$ & $118(24.38 \%)$ & $165(26.03 \%)$ & $22(23.91 \%)$ \\
\hline CHF: yes, no. (\%) & $105(7.23 \%)$ & $22(4.55 \%)$ & $38(5.99 \%)$ & $7(7.61 \%)$ \\
\hline
\end{tabular}

fusion group than in the nonfusion group $(5.21 \%$ vs $7.81 \%$, respectively). New decompression was more frequent in the nonfusion group (7.72\% vs $4.69 \%)$. The overall need for reoperation was higher in the nonfusion group than in the fusion group (12.7\% vs $8.16 \%)$.

\section{Secondary Outcomes}

Length of stay was greater for the nonfusion group than the fusion group (6 vs 4 days, respectively). Discharge home occurred more frequently in the fusion group than in the nonfusion group (80.73\% vs $72.53 \%$ ). Complications at the index hospitalization were more common in the nonfusion group than the fusion group (34.95\% vs $23.96 \%$ ). Complications within 30 days of operation were observed in $16.49 \%$ and $24.64 \%$ of the fusion and nonfusion groups, respectively. Emergency room admissions were observed in $30.38 \%$ of the fusion group and in $35.76 \%$ of the nonfusion group over the 12-month postoperative period. Readmissions to the hospital within 12 months postoperatively were observed in $38.73 \%$ of the nonfusion group and $26.39 \%$ of the fusion group. Outpatient services were more numerous for the nonfusion group with a median of 109 services, whereas the fusion group had a median of 82 services. Median payments for outpatient services were higher for the nonfusion group $(\$ 14,415)$ than for the fusion group $(\$ 9,669)$. The median number of medication refills was 106 for the fusion group and 98 for the nonfusion group. Overall payments were greater for the nonfu- sion group, totaling $\$ 33,137$ compared to $\$ 23,426$ for the fusion group. However, combined payments that included the index hospitalization and outpatient costs totaled $\$ 70,748$ for the nonfusion group compared to $\$ 85,750$ for the fusion group.

\section{Discussion}

The management of spine infection is nuanced and complex with great variability in treatment options and prolonged antibiotic therapy. ${ }^{21,33}$ Limited data regarding the longer-term results of decompression with and without fusion for spine infection have been available to inform clinical practice and counsel patients. We report a 12-month postoperative reoperation rate of $8.16 \%$ for decompression with fusion and a rate of $12.7 \%$ for decompression without fusion. These values are in alignment with the reoperation rates for other spinal conditions. ${ }^{18,25}$ Although there appears to be decreased rates of reoperation and new infection in the fusion group after the treatment of spinal infection, comparative analyses between surgical cohorts was not conclusive given the lack of information on preoperative imaging, disease severity, and additional factors that were not available in a retrospective large database study. These factors, as well as the baseline characteristics, pathology of the surgical infection, and treatment approach, may dictate the decision to pursue fusion in spinal infection. 
TABLE 5. Outcome comparison of fusion groups with and without surgery in the 12 months prior to decompression for spinal infection

\begin{tabular}{|c|c|c|c|c|}
\hline \multirow[b]{2}{*}{ Variable } & \multicolumn{2}{|c|}{ No Op in 12 Mos Prior to Decompression } & \multicolumn{2}{|c|}{ Op in 12 Mos Prior to Decompression } \\
\hline & w/o Fusion & w/ Fusion & w/o Fusion & w/ Fusion \\
\hline No. $(\%)$ & $1452(75 \%)$ & $484(25 \%)$ & $634(87.33 \%)$ & $92(12.67 \%)$ \\
\hline \multicolumn{5}{|l|}{ Index hospitalization outcomes } \\
\hline LOS in days, median (IQR) & $6(2,11)$ & $4(3,6)$ & $6(4,10)$ & $5(3,9)$ \\
\hline Payment, median (IQR) & $\$ 26,087(\$ 12961, \$ 58382)$ & $\$ 52,784(\$ 34108, \$ 90534)$ & $\$ 30,336(\$ 17896, \$ 55360)$ & $\$ 61,952(\$ 33863, \$ 97673)$ \\
\hline Discharge home, no. (\%) & $1012(69.70 \%)$ & $396(81.82 \%)$ & $501(79.02 \%)$ & $69(75 \%)$ \\
\hline Complications, no. (\%) & $460(31.68 \%)$ & $111(22.93 \%)$ & $269(42.43 \%)$ & $27(29.35 \%)$ \\
\hline \multicolumn{5}{|l|}{$\begin{array}{l}\text { Postdischarge outcomes, } 30 \\
\text { days, no. (\%) }\end{array}$} \\
\hline Complications & $312(21.49 \%)$ & $74(15.29 \%)$ & $202(31.86 \%)$ & $21(22.83 \%)$ \\
\hline ER admission & $216(14.88 \%)$ & $51(10.54 \%)$ & $124(19.56 \%)$ & $12(13.04 \%)$ \\
\hline \multicolumn{5}{|l|}{$\begin{array}{l}\text { Postdischarge outcomes, } 12 \\
\text { mos, no. (\%) }\end{array}$} \\
\hline New fusion & $96(6.61 \%)$ & $25(5.17 \%)$ & $67(10.57 \%)$ & $5(5.43 \%)$ \\
\hline Re-fusion & $18(1.24 \%)$ & $16(3.31 \%)$ & $33(5.21 \%)$ & $7(7.61 \%)$ \\
\hline New decompression & $98(6.75 \%)$ & $22(4.55 \%)$ & $63(9.94 \%)$ & $5(5.43 \%)$ \\
\hline At least 1 of the above & $156(10.74 \%)$ & $38(7.85 \%)$ & $109(17.19 \%)$ & $9(9.78 \%)$ \\
\hline ER admission & $493(33.95 \%)$ & $144(29.75 \%)$ & $253(39.91 \%)$ & $31(33.7 \%)$ \\
\hline \multicolumn{5}{|l|}{ Hospital admissions } \\
\hline Admitted, no. (\%) & $526(36.23 \%)$ & $122(25.21 \%)$ & $282(44.48 \%)$ & $30(32.61 \%)$ \\
\hline $\begin{array}{l}\text { No. of readmissions, me- } \\
\text { dian (IQR) }\end{array}$ & $0(0,1)$ & $0(0,1)$ & $0(0,1)$ & $0(0,1)$ \\
\hline Payments, median (IQR) & $\$ 0(\$ 0, \$ 14716)$ & $\$ 0(\$ 0, \$ 0)$ & $\$ 0(\$ 0, \$ 29611)$ & $\$ 0(\$ 0, \$ 7394)$ \\
\hline \multicolumn{5}{|l|}{ Outpatient services } \\
\hline $\begin{array}{l}\text { No. of services, median } \\
(I Q R)\end{array}$ & $96(46,180)$ & $108(42,191)$ & $137(80,230)$ & $106(59,166)$ \\
\hline $\begin{array}{l}\text { Outpatient payments, } \\
\text { median (IQR) }\end{array}$ & $\$ 6,091(\$ 631, \$ 16619)$ & $\$ 6,188(\$ 1143, \$ 17430)$ & $\$ 18,984(\$ 9402, \$ 34837)$ & $\$ 11,138(\$ 5916, \$ 21301)$ \\
\hline \multicolumn{5}{|l|}{ Medication refills } \\
\hline No. of refills, median (IQR) & $87(30,177)$ & $108(42,191)$ & $117(38,212)$ & $97(12,183)$ \\
\hline Payments, median (IQR) & $\$ 6,091(\$ 631, \$ 16619)$ & $\$ 6,188(\$ 1143, \$ 17430)$ & $\$ 8,535(\$ 610, \$ 22197)$ & $\$ 6,292(\$ 102, \$ 15125)$ \\
\hline Overall payments & $\$ 27,830(\$ 11556, \$ 66788)$ & $\$ 22,811(\$ 107498, \$ 44038)$ & $\$ 43,998(\$ 20475, \$ 86064)$ & $\$ 28,216(\$ 11800, \$ 51720)$ \\
\hline $\begin{array}{c}\text { Combined (index hospital + } \\
\text { overall), median (IQR) }\end{array}$ & $\$ 64,792(\$ 32661, \$ 133126)$ & $\$ 83,622(\$ 52981, \$ 130075)$ & $\$ 82,639(\$ 50537, \$ 137857)$ & $\$ 101,022(\$ 61409, \$ 149745)$ \\
\hline
\end{tabular}

\section{Readmissions for Infection}

In our study, readmission rates for infection were $11.25 \%$ in the nonfusion cohort and 3.99\% in the fusion cohort. Infection rates in both groups were higher than most reported averages for postoperative surgical site infection after spine surgery, which range from $0.7 \%$ to $6 \% .^{14,19,26,31}$ It is interesting to know that rehospitalization for infection following initial surgical treatment of spinal infection reduces unfavorable outcomes, including chronic pain, sepsis, deformity, pseudarthrosis, and neurological compromise..$^{11,33}$ Additionally, increased length of stay and healthcare utilization have been observed in cohorts with readmission for infection. ${ }^{15,34}$ Whitmore and colleagues have also noted that surgical site infection after spine surgery adds $\$ 4,067$ to the payment for care. ${ }^{34}$ This finding is consistent with our finding that higher infection rates were related to higher overall health resource utilization costs within 12 months postoperatively. The low rates of rehospitalization after fusion are notable and possibly attributable to the increasing use of titanium implants for spinal fusion in the face of infection, which carry a much lower risk of glycocalyx formation. ${ }^{3}$

\section{Health Resource Utilization}

Overall payments including postdischarge services, outpatient services, and medication payments within 12 months after surgery for the nonfusion group totaled $\$ 33,137$ for the nonfusion group and $\$ 23,426$ for the fusion group. The index hospitalization cost a median $\$ 52,784$ for the fusion group and $\$ 27,883$ for the nonfusion group. Therefore, spinal infections consume significant healthcare 
TABLE 6. Outcome comparison among fusion groups ( $\geq 12$ months of follow-up)

\begin{tabular}{|c|c|c|}
\hline Variable & w/o Fusion & w/ Fusion \\
\hline No. $(\%)$ & $2086(78.36 \%)$ & $576(21.64 \%)$ \\
\hline \multicolumn{3}{|l|}{ Index hospitalization outcomes } \\
\hline LOS, median (IQR) & $6(3,11)$ & $4(3,6)$ \\
\hline Payment, median (IQR) & $\$ 27,883(\$ 14203, \$ 57345)$ & $\$ 52,784(\$ 34108, \$ 90534)$ \\
\hline Discharge home, no. (\%) & $1513(72.53 \%)$ & $465(80.73 \%)$ \\
\hline Complications, no. (\%) & $729(34.95 \%)$ & $138(23.96 \%)$ \\
\hline \multicolumn{3}{|l|}{ Postdischarge outcomes at 30 days, no. (\%) } \\
\hline Complications & $514(24.64 \%)$ & $95(16.49 \%)$ \\
\hline ER admissions & $340(16.30 \%)$ & $63(10.94 \%)$ \\
\hline \multicolumn{3}{|l|}{ Postdischarge outcomes at 12 mos, no. (\%) } \\
\hline New fusion & $163(7.81 \%)$ & $30(5.21 \%)$ \\
\hline Re-fusion & $51(2.44 \%)$ & $23(3.99 \%)$ \\
\hline New decompression & $161(7.72 \%)$ & $27(4.69 \%)$ \\
\hline At least 1 of the above & $265(12.7 \%)$ & $47(8.16 \%)$ \\
\hline ER admission & $746(35.76 \%)$ & $175(30.38 \%)$ \\
\hline New infection & $235(11.27 \%)$ & $23(3.99 \%)$ \\
\hline \multicolumn{3}{|l|}{ Hospital admissions at 12 mos postop } \\
\hline Admitted, no. (\%) & $808(38.73 \%)$ & $152(26.39 \%)$ \\
\hline No. of readmissions, median (IQR) & $0(0,1)$ & $0(0,1)$ \\
\hline Payments, median (IQR) & $\$ 0(\$ 0, \$ 18027)$ & $\$ 0(\$ 0, \$ 1051)$ \\
\hline \multicolumn{3}{|l|}{ Outpatient services } \\
\hline No. of services, median (IQR) & $109(57,198)$ & $82(50,138)$ \\
\hline Outpatient payments, median (IQR) & $\$ 14,415(\$ 5691, \$ 29400)$ & $\$ 9,669(\$ 4691, \$ 19327)$ \\
\hline \multicolumn{3}{|l|}{ Medication refills } \\
\hline No. of refills, median (IQR) & $98(33,186)$ & $106(40,189)$ \\
\hline Payments, median (IQR) & $\$ 6,637(\$ 624, \$ 17732)$ & $\$ 6,188(\$ 886, \$ 17409)$ \\
\hline Overall payments & $\$ 33,137(\$ 13577, \$ 72705)$ & $\$ 23,426(\$ 10702, \$ 46442)$ \\
\hline Combined payments (index hospital + overall), median (IQR) & $\$ 70,748(\$ 37678, \$ 135020)$ & $\$ 85,750(\$ 53539, \$ 131403)$ \\
\hline
\end{tabular}

resources regardless of whether the treatment includes fusion. For the fusion group, inpatient services were more than double the outpatient services payments. The nonfusion cohort had a greater overall payment for postdischarge and outpatient services than the index hospitalization cost. Specifically, length of stay and time until discharge home were longer for the nonfusion group than for the fusion group. Index hospitalization complications were more common in the nonfusion group than the fusion group (34.95\% vs $23.96 \%$, respectively).

\section{Reoperation Rates}

The total reoperation rate within 12 months postoperatively was $12.7 \%$ in the nonfusion and $8.16 \%$ of fusion cohorts. The reoperation rate of $8.16 \%$ for fusion was similar to the rate for other fusion procedures after 12 months, which has been reported to be $6.1 \%-7.2 \%$ in previous studies on degenerative spine surgery. ${ }^{16,24}$ Therefore, the use of fusion to treat spinal infection does not result in more re-fusion procedures than have been reported for other spinal disorders. Reoperation has been described to be more likely after fusion than after decompression alone. ${ }^{18}$ However, we found a higher incidence of reop- eration after decompression alone than after fusion. Possible reasons for the difference include selection bias with greater disease severity in the nonfusion group. Another possible reason is that infections are better treated with the addition of fusion. Without preoperative imaging and neurological status data, however, it was not possible to determine the reasons for differences in reoperation rates between the two groups. Nevertheless, it appears that both treatment options are safe in treating spinal infections in appropriately selected patients. If fusion is performed, one should consider the use of titanium implants, the use of iliac crest bone graft, and the avoidance of polyetheretherketone (PEEK) implants to reduce reinfection hospitalization rates. 3,13

\section{Study Strengths and Limitations}

MarketScan has been heavily used in medical research. The reason for its popularity is its geographic coverage of the entire US and inclusion of very large sample sizes. In addition, it has longitudinal data, which allows a researcher to track individuals as they use healthcare over time. Thus, it permits an overview of healthcare utilization (inpatient, outpatient, medications, etc.) and payment as 
well as clinical outcomes in the real world and throughout the US. Nonetheless, our analysis has some noteworthy shortcomings. One significant limitation is the inability to compare the cohorts of the fusion and nonfusion groups. The two surgical options discussed are not interchangeable for spinal infection and are not being compared as therapeutic options for spinal infection. Clinical information such as extent of the clinical problem and imaging studies are not available in this database; therefore, the clinical decision-making involved in each case could not be evaluated. Further, given the inability to identify the location of infection for the nonfusion group, we did not differentiate between cervical versus thoracolumbar infections. While infection location could be determined for the fusion group, the cervical sample size was not sufficiently large to include in a meaningful separate analysis. Another limitation of MarketScan is that factors that do not influence reimbursement but are very important for patient decision-making (disease severity, duration of problem, and imaging) are not available. Therefore, our results should be interpreted cautiously. Additionally, there was an inability to control for confounding factors by indication of the procedure performed given the lack of data in this database regarding additional factors that impact the treatment chosen by the surgeon. Prior spine surgery, for example, may increase the incidence of secondary infection or surgical site infection for both groups and alter the surgical approach. To mitigate the confounding factor of previous spinal surgery prior to the procedure for spinal infection, separate analyses were conducted for the fusion and nonfusion groups with and without spine surgery in the 12 months prior to the decompression. There was also an inability to quantify the severity of postoperative complications and an inability to obtain patient quality-of-life and patient-reported outcomes. With regard to the new infection designation, one shortcoming is that we cannot determine from the claims data if a postoperative infection represents a new infection at a different level or from a different pathogen versus a recurrence of infection with a similar vertebral level and pathogen. Another limitation is the use of ICD-9/10 and CPT codes, which are entered by coders and thus prone to human error. In light of these strengths and limitations, we believe that our study design allows an insightful view of the comparative effectiveness of decompression with fusion versus decompression without fusion for spinal infection in the US.

\section{Conclusions}

With this large cohort study and 12-month follow-up data, we have added important analysis information and considerations to help surgeons and patients make treatment decisions related to spinal infections. Although the recurrence of infection, reoperation rates, and complications were higher in patients treated with decompression alone versus decompression with fusion, both treatments for spinal infection have been shown to improve patient outcomes by reducing infection recurrence and reoperation rates following the index surgery. These findings along with factors such as imaging characteristics, disease severity, extent of bony resection, and spinal instability may help surgeons decide whether to recommend adding fusion at the time of a patient's initial surgery. Additional comparative studies can help to identify optimal treatment approaches and additional ways to reduce complications.

\section{References}

1. Arko L IV, Quach E, Nguyen V, Chang D, Sukul V, Kim BS: Medical and surgical management of spinal epidural abscess: a systematic review. Neurosurg Focus 37(2):E4, 2014

2. Butler JS, Shelly MJ, Timlin M, Powderly WG, O’Byrne JM: Nontuberculous pyogenic spinal infection in adults: a 12-year experience from a tertiary referral center. Spine (Phila Pa 1976) 31:2695-2700, 2006

3. Chauhan A, Bernardin A, Mussard W, Kriegel I, Estève M, Ghigo JM, et al: Preventing biofilm formation and associated occlusion by biomimetic glycocalyxlike polymer in central venous catheters. J Infect Dis 210:1347-1356, 2014

4. Cornett CA, Vincent SA, Crow J, Hewlett A: Bacterial spine infections in adults: evaluation and management. J Am Acad Orthop Surg 24:11-18, 2016

5. Darouiche RO: Spinal epidural abscess. N Engl J Med 355:2012-2020, 2006

6. de Lucas EM, González Mandly A, Gutiérrez A, Pellón R, Martín-Cuesta L, Izquierdo J, et al: CT-guided fine-needle aspiration in vertebral osteomyelitis: true usefulness of a common practice. Clin Rheumatol 28:315-320, 2009

7. Elixhauser A, Steiner C, Harris DR, Coffey RM: Comorbidity measures for use with administrative data. Med Care 36:8-27, 1998

8. Finucane TE, Christmas C, Travis K: Tube feeding in patients with advanced dementia: a review of the evidence. JAMA 282:1365-1370, 1999

9. Hadjipavlou AG, Mader JT, Necessary JT, Muffoletto AJ: Hematogenous pyogenic spinal infections and their surgical management. Spine (Phila Pa 1976) 25:1668-1679, 2000

10. Hansen LG, Chang S: Health Research Data for the Real World: The Thomson Reuters MarketScan Databases. Ann Arbor, MI: Truven Health Analytics, 2012

11. Hegde V, Meredith DS, Kepler CK, Huang RC: Management of postoperative spinal infections. World J Orthop 3:182189,2012

12. Hopkinson N, Stevenson J, Benjamin S: A case ascertainment study of septic discitis: clinical, microbiological and radiological features. QJM 94:465-470, 2001

13. Jonkergouw J, van de Vijfeijken SE, Nout E, Theys T, Van de Casteele E, Folkersma H, et al: Outcome in patient-specific PEEK cranioplasty: a two-center cohort study of 40 implants. J Craniomaxillofac Surg 44:1266-1272, 2016

14. Kanayama M, Hashimoto T, Shigenobu K, Oha F, Togawa D: Effective prevention of surgical site infection using a Centers for Disease Control and Prevention guideline-based antimicrobial prophylaxis in lumbar spine surgery. J Neurosurg Spine 6:327-329, 2007

15. Khan IU, Janjua MB, Hasan S, Shah S: Surgical site infection in lumbar surgeries, pre and postoperative antibiotics and length of stay: a case study. J Ayub Med Coll Abbottabad 21:135-138, 2009

16. Kim CH, Chung CK, Park CS, Choi B, Hahn S, Kim MJ, et al: Reoperation rate after surgery for lumbar spinal stenosis without spondylolisthesis: a nationwide cohort study. Spine J 13:1230-1237, 2013

17. Kuklo TR, Potter BK, Bell RS, Moquin RR, Rosner MK: Single-stage treatment of pyogenic spinal infection with titanium mesh cages. J Spinal Disord Tech 19:376-382, 2006

18. Martin BI, Mirza SK, Comstock BA, Gray DT, Kreuter W, Deyo RA: Reoperation rates following lumbar spine surgery and the influence of spinal fusion procedures. Spine (Phila Pa 1976) 32:382-387, 2007

19. Nota SP, Braun Y, Ring D, Schwab JH: Incidence of surgical 
site infection after spine surgery: what is the impact of the definition of infection? Clin Orthop Relat Res 473:16121619, 2015

20. Parikh AA, Robinson J, Zaydfudim VM, Penson D, Whiteside MA: The effect of health insurance status on the treatment and outcomes of patients with colorectal cancer. J Surg Oncol 110:227-232, 2014

21. Przybylski GJ, Sharan AD: Single-stage autogenous bone grafting and internal fixation in the surgical management of pyogenic discitis and vertebral osteomyelitis. J Neurosurg 94 (1 Suppl): 1-7, 2001

22. Quan H, Sundararajan V, Halfon P, Fong A, Burnand B, Luthi JC, et al: Coding algorithms for defining comorbidities in ICD-9-CM and ICD-10 administrative data. Med Care 43:1130-1139, 2005

23. Sapico FL, Montgomerie JZ: Pyogenic vertebral osteomyelitis: report of nine cases and review of the literature. Rev Infect Dis 1:754-776, 1979

24. Sato S, Yagi M, Machida M, Yasuda A, Konomi T, Miyake A, et al: Reoperation rate and risk factors of elective spinal surgery for degenerative spondylolisthesis: minimum 5-year follow-up. Spine J 15:1536-1544, 2015

25. Scheer JK, Tang JA, Smith JS, Klineberg E, Hart RA, Mundis GM Jr, et al: Reoperation rates and impact on outcome in a large, prospective, multicenter, adult spinal deformity database: clinical article. J Neurosurg Spine 19:464-470, 2013

26. Schimmel JJ, Horsting PP, de Kleuver M, Wonders G, van Limbeek J: Risk factors for deep surgical site infections after spinal fusion. Eur Spine J 19:1711-1719, 2010

27. Silber JS, Anderson DG, Vaccaro AR, Anderson PA, McCormick P: Management of postprocedural discitis. Spine J 2:279-287, 2002

28. Skaf GS, Domloj NT, Fehlings MG, Bouclaous CH, Sabbagh AS, Kanafani ZA, et al: Pyogenic spondylodiscitis: an overview. J Infect Public Health 3:5-16, 2010

29. Stokes ME, Davis CS, Koch GG: Categorical Data Analysis Using the SAS System, ed 2. Cary, NC: SAS Institute, 2000

30. Stüer C, Stoffel M, Hecker J, Ringel F, Meyer B: A staged treatment algorithm for spinal infections. J Neurol Surg A Cent Eur Neurosurg 74:87-95, 2013

31. Veeravagu A, Patil CG, Lad SP, Boakye M: Risk factors for postoperative spinal wound infections after spinal decompression and fusion surgeries. Spine (Phila Pa 1976) 34:1869-1872, 2009

32. Vollmer DG, Tandon N: Infection of the spine, in Winn HR (ed): Youmans Neurological Surgical, ed 6. Philadelphia: Saunders/Elsevier, 2011, pp 3216-3232

33. Weinstein MA, McCabe JP, Cammisa FP Jr: Postoperative spinal wound infection: a review of 2,391 consecutive index procedures. J Spinal Disord 13:422-426, 2000

34. Whitmore RG, Stephen J, Stein SC, Campbell PG, Yadla S, Harrop JS, et al: Patient comorbidities and complications after spinal surgery: a societal-based cost analysis. Spine (Phila Pa 1976) 37:1065-1071, 2012

\section{Disclosures}

The authors report no conflict of interest concerning the materials or methods used in this study or the findings specified in this paper.

\section{Author Contributions}

Conception and design: Boakye, Dietz, Wang, Drazin. Acquisition of data: Dietz, Alhourani, Drazin. Analysis and interpretation of data: Dietz, Ugiliweneza, Nuño, Drazin. Drafting the article: Dietz, Sharma, Alhourani, Drazin. Critically revising the article: Boakye, Dietz, Sharma, Alhourani, Wang, Nuño. Reviewed submitted version of manuscript: Dietz, Sharma, Wang. Statistical analysis: Ugiliweneza.

\section{Correspondence}

Maxwell Boakye: University of Louisville, School of Medicine, Louisville, KY. maxwell.boakye@ulp.org. 